\title{
Gene expression profiling of the 8q22-24 position in human breast cancer: TSPYL5, MTDH, ATAD2 and CCNE2 genes are implicated in oncogenesis, while WISP1 and EXT1 genes may predict a risk of metastasis
}

\author{
AFSOON TAGHAVI ${ }^{1}$, MOHAMMAD ESMAEIL AKBARI ${ }^{1}$, MOHAMMAD HASHEMI-BAHREMANI $^{2}$, \\ NAHID NAFISSI ${ }^{1}$, AHAD KHALILNEZHAD $^{3}$, SEYED MOHAMMAD POORHOSSEINI ${ }^{4}$, \\ FEYZOLLAH HASHEMI-GORJI $^{5}$ and VAHID REZA YASSAEE ${ }^{4,5}$
}

\begin{abstract}
${ }^{1}$ Department of Cellular and Molecular Biology, Cancer Research Center; ${ }^{2}$ Department of Pathology, Imam Hossein Hospital; Departments of ${ }^{3}$ Immunology and ${ }^{4}$ Medical Genetics, Faculty of Medicine, Shahid Beheshti University of Medical Sciences; ${ }^{5}$ Molecular Diagnostic Laboratory, Genomic Research Center, Shahid Beheshti University of Medical Sciences, Ayatollah Taleghani Educational Hospital, Tehran 1985717413, Iran
\end{abstract}

Received January 28, 2016; Accepted July 28, 2016

DOI: 10.3892/ol.2016.5218

\begin{abstract}
Gene expression profiling has been suggested to predict breast cancer outcome. The prognostic value of the 8q22-24 position in breast cancer remains to be elucidated. The present study evaluated expression patterns of the genes located at this position in metastatic and non-metastatic breast cancer. A total of 85 patients with recurrent/metastatic $(n=15)$ and non-metastatic $(n=70)$ early-stage, estrogen receptor-positive and lymph node-negative breast tumors were included. In addition, 15 normal breast tissue samples were used as controls. Demographic and clinical features were recorded. Subsequently, mRNA copy numbers of exostosin glycosyltransferase 1 (EXT1), WNT1 inducible signaling pathway protein 1 (WISP1), ATPase family, AAA domain containing 2 (ATAD2), TSP-like 5 (TSPYL5), metadherin (MTDH) and cyclin E2 (CCNE2) genes were measured by reverse transcription-quantitative polymerase chain reaction assay. The expression of EXT1 and WISPI exhibited a significant decline in the metastatic breast cancer group compared to the control $(\mathrm{P}=0.015$ and $\mathrm{P}=0.012$, respectively). The expression of TSPYL5, MTDH and ATAD2 was significantly decreased in the metastatic $(\mathrm{P}=0.002, \mathrm{P}=0.018$ and $\mathrm{P}=0.016$, respectively) and non-metastatic $(\mathrm{P}=0.038, \mathrm{P}=0.045$ and $\mathrm{P}=0.000$, respectively) breast cancer groups compared with the control. The expression of $C C N E 2$ in the metastatic and non-metastatic
\end{abstract}

Correspondence to: Dr Vahid Reza Yassaee, Molecular Diagnostic Laboratory, Genomic Research Center, Shahid Beheshti University of Medical Sciences, Ayatollah Taleghani Educational Hospital, Araabi Street, Yaman Avenue, Chamran High Way, Tehran 1985717413, Iran

E-mail: v.yassaee-grc@sbmu.ac.ir

Key words: breast cancer, metastasis, gene expression breast cancer groups was significantly increased compared with the control $(\mathrm{P}=0.002$ and $\mathrm{P}=0.001$, respectively). WISPI expression demonstrated a correlation with patient age and tumor size, and TSPYL5 expression was correlated with lymphovascular invasion. None of the genes investigated exhibited any correlation with stage and grade of disease. The TSPYL5, MTDH,ATAD2 and CCNE2 genes may be implicated in the pathogenesis of human breast cancer, while the WISP1 and EXT1 genes may have the potential to serve as promising indicators of the risk of metastasis. However, further studies are required to validate these results.

\section{Introduction}

Breast cancer is the most common malignancy among women worldwide (1), with an intrinsically heterogeneous etiology, but similar clinical manifestations in the majority of cases (2). A number of studies have reported that genetic and environmental factors contribute to breast cancer pathogenesis and progression (3-5). For example, several proliferation and oncogenic genes, including breast cancer (BRCA) 1, BRCA2, MYC, tumor protein 53, retinoblastoma $1, J U N$, cyclin-dependent kinase inhibitor $2 \mathrm{~A}$, human epidermal growth factor receptor 2-neu, cyclin D1 and cyclin E, have been identified in breast cancer (6-8). Therefore, genetic and molecular screening of patients has been proposed as useful to predict disease behavior, response to anti-cancer therapeutics and patient survival $(9,10)$.

A growing body of evidence has revealed that abnormalities at certain chromosomal positions lead to various tumor behaviors, including progression, resistance to chemotherapy and spread to other organs (11-13). Dellas et al (11) suggested that aberrations in chromosomes 11p and 18q may be associated with poor prognosis and progression of ductal breast cancer. In addition, Horlings et al (13) reported a strong correlation between genomic differences and various gene expression signatures leading to poor prognosis in breast cancer. Furthermore, it has 
been reported that aberrations in chromosome $8 \mathrm{q}$ may be associated with resistance to chemotherapy in breast cancer (14).

Association of the 8q22-24 position, containing WNT1 inducible signaling pathway protein 1 (WISPl), exostosin glycosyltransferase 1 (EXT1), ATPase family, AAA domain containing 2 (ATAD2), TSP-like 5 (TSPYL5), metadherin $(M T D H)$ and cyclin E2 (CCNE2) genes, with breast cancer and other carcinomas has been proposed by numerous investigators using varied molecular approaches, including genome wide association study, array-comparative genomic hybridization and gene expression profiling methods (13-17). However, existing data are conflicting. By way of example, WISP1, a member of the CCN family, has shown contradictory functions in the context of cancer (17-20). Davies et al (19) suggested varying prognostic values for the CCN family members, including WISP1, WISP2 and WISP3, in human breast cancer; WISP1 was observed to be a tumor suppressor, WISP2 was a stimulator of tumor aggressiveness and WISP3 remained undefined regarding a beneficial or detrimental role. However, in another investigation, contrasting roles were observed for WISPI and WISP2 in human colorectal cancer (20); WISPI appeared to be a stimulator of tumor aggressiveness and WISP2 was characterized as a tumor suppressor.

There have been few studies on the role of 8q22-24 genes in the pathogenesis of breast cancer. Overexpression of ATAD2 has been reported to drive survival of breast cancer cells, resulting in a poor prognosis (21). Inhibition of $M T D H$ has been demonstrated to sensitize breast cancer cells to anti-cancer agents $(22,23)$. The TSPYL5 gene has been suggested to have a causative role in breast tumorigenesis (24). The CCNE2 gene has been demonstrated to have a role in the invasiveness of breast cancer cells (25). To the best of our knowledge, there have been no investigations into the role of EXT1 in the pathogenesis of breast carcinoma.

The present study performed an investigation into the expression patterns of EXT1, WISP1, ATAD2, TSPYL5, MTDH and $C C N E 2$ genes, and compared them between metastatic and non-metastatic breast cancer in order to examine their potential as prognostic markers for the risk of metastasis in humans.

\section{Materials and methods}

Patients and tumor samples. This retrospective study primarily included 1705 breast tumor samples obtained from the Bio Bank of the Cancer Research Center of Shahid Beheshti University of Medical Sciences (Tehran, Iran). The tissues were taken from breast cancer patients who underwent either breast-conserving surgery or modified radical mastectomy at Khatam-Ol-Anbia Specialty and Subspecialty Hospital of Tehran (Tehran, Iran) between August 2002 and December 2012. Only estrogen receptor (ER)-positive, lymph-node negative tumors with tumors stages I and II and tumor size $<5 \mathrm{~cm}$ were analyzed. The patients were divided into metastatic and non-metastatic groups based on a 5-year follow-up period following the curative surgery. Demographic features and clinical data of the patients were collected. In addition, 15 matched normal breast tissues, taken from volunteer healthy women who underwent mammoplasty between June 2012 and April 2013, were used as control. Patients had previously signed an informed consent on the prospective use of their specimen for study purposes. The study procedure and use of clinical information of the patients was approved by the ethical committee of Shahid Beheshti University of Medical Sciences. In addition, identity and personal information of all participants were not disclosed at any stage of the study and/or following the study conclusion.

RNA extraction. Total RNA was extracted from already paraffin-embedded tumor samples and normal breast tissues using the RNeasy FFPE kit (Qiagen GmbH, Hilden, Germany), according to the manufacturer's protocol. Briefly, the paraffin was removed from samples by xylene. Subsequently, sample lysis was performed by proteinase $\mathrm{K}$ (Qiagen $\mathrm{GmbH}$ ) digestion for $15 \mathrm{~min}$, followed by incubation at $80^{\circ} \mathrm{C}$ for $15 \mathrm{~min}$. Following incubation, the genomic DNA was effectively removed by DNase and DNase Booster Buffer (Qiagen $\mathrm{GmbH}$ ) treatment for $15 \mathrm{~min}$. Finally, concentrated RNA was purified using RNeasy MinElute spin columns (Qiagen $\mathrm{GmbH}$ ) according to the manufacturer's protocol, and eluted in a volume of $20 \mu \mathrm{l}$ on the QIAcube (Qiagen $\mathrm{GmbH}$ ).

Complementary DNA (cDNA) synthesis. The total RNA was directly converted to cDNA using the RT2 PreAMP cDNA Synthesis kit (Qiagen $\mathrm{GmbH}$ ), according to the manufacturer's protocol. Briefly, $1 \mu \mathrm{l}$ of total RNA was added to $9 \mu \mathrm{l}$ of reverse-transcription mix and $10 \mu \mathrm{l}$ of genomic DNA elimination mix, and the final volume of $20 \mu \mathrm{l}$ was subjected to reverse transcription at $42^{\circ} \mathrm{C}$ for $30 \mathrm{~min}$. The reaction was terminated at $95^{\circ} \mathrm{C}$ for $5 \mathrm{~min}$ followed by a pause at $4^{\circ} \mathrm{C}$ (to remove the microtubes), and then samples were preserved at $-20^{\circ} \mathrm{C}$ until use.

Quantitative polymerase chain reaction ( $q P C R)$ assay. The mRNA copy numbers of EXT1, WISP1, ATAD2, TSPYL5, $M T D H, C C N E 2$ and glyceraldehyde-3-phosphate dehydrogenase $(G A P D H)$ genes were measured by SYBR green-based qPCR using the respective specific pairs of primers (Table I). All reactions were performed in duplicate using the 7500 Fast Real-Time PCR System (Applied Biosystems; Thermo Fisher Scientific, Inc., Waltham, MA, USA) and Takara Bio SYBR Premix Ex Taq (Tli RNase H Plus) master mix (Takara Bio, Inc., Otsu, Japan), according to the manufacturer's protocol, in a total reaction volume of $25 \mu \mathrm{l}$. The thermal profile of the reaction was as follows: Initial denaturation at $95^{\circ} \mathrm{C}$ for $30 \mathrm{sec}$, followed by 40 consecutive two-step cycles of PCR $\left(95^{\circ} \mathrm{C}\right.$ for $5 \mathrm{sec}$ and $60^{\circ} \mathrm{C}$ for $30 \mathrm{sec}$ ), and termination in a dissociation stage (increasing the temperature from 65 to $95^{\circ} \mathrm{C}$, rising by $1^{\circ} \mathrm{C}$ each step, halting for $90 \mathrm{sec}$ of pre-melt conditioning on the first step and $5 \mathrm{sec}$ for each subsequent step). The cycling threshold values of the target genes were normalized to that of $G A P D H$ as an internal control and relative gene expression was calculated by $2^{(-\Delta \Delta \mathrm{Cq})}$ method as follows (26): Relative gene expression $=2^{-\Delta \Delta \mathrm{Cq}} . \Delta \Delta \mathrm{Cq}=\Delta \mathrm{Cq}_{\text {case }}-\Delta \mathrm{Cq}_{\text {control }}$. $\Delta \mathrm{Cq}=\mathrm{Cq}_{\text {target }}-\mathrm{Cq}_{\mathrm{GAPDH}}$.

Statistical analysis. For statistical analysis, the $\chi^{2}$ or Fisher's exact, Mann-Whitney $\mathrm{U}$ or independent $t$ test, and analysis of variance or Kruskal-Wallis (followed by post-hoc pairwise comparisons) tests were performed using SPSS version 20 (IMB SPSS, Armonk, NY, USA). In addition, associations between the variables were examined by parametric Pearson and non-parametric Spearman's correlation tests. GraphPad Prism 5 for Windows (GraphPad Software, Inc., La Jolla, CA, 
Table I. Oligonucleotide sequences of the primers used in the present study.

\begin{tabular}{|c|c|c|c|}
\hline Primer & Sequence, 5'-3' & Annealing temperature, ${ }^{\circ} \mathrm{C}$ & Product length, bp \\
\hline \multicolumn{4}{|l|}{ EXT1 } \\
\hline Forward & 5'-CTTCGTTCCTTGGGATCAAT-3' & 55.42 & \multirow[t]{2}{*}{95} \\
\hline Reverse & 5'-TGCCTTTGTAGATGCTGGAG-3' & 57.59 & \\
\hline \multicolumn{4}{|l|}{ WISP1 } \\
\hline Forward & 5'-CAAGGCTGGATAACAGCTCA-3' & 57.59 & \multirow[t]{2}{*}{87} \\
\hline Reverse & 5'-TTCCCAAATTGAGATGCAAA-3' & 53.62 & \\
\hline \multicolumn{4}{|l|}{ ATAD2 } \\
\hline Forward & 5'-CCAGACAGCAGGCTGATAAA-3' & 57.59 & \multirow[t]{2}{*}{137} \\
\hline Reverse & 5'-ACGCACTTCAACATCACCAT-3' & 58.10 & \\
\hline \multicolumn{4}{|l|}{ TSPYL5 } \\
\hline Forward & 5'-TGCACAAGTCTCCCTGCTAC-3' & 59.68 & \multirow[t]{2}{*}{87} \\
\hline Reverse & 5'-CAGAGGCCAACATGAAGAGA-3' & 57.22 & \\
\hline \multicolumn{4}{|l|}{$M T D H$} \\
\hline Forward & 5'-TGCCGCCAATACTACAAGAG-3' & 57.69 & \multirow[t]{2}{*}{105} \\
\hline Reverse & 5'-GTTTGGGAGATTCCCAGCTA-3' & 56.90 & \\
\hline \multicolumn{4}{|l|}{ CCNE2 } \\
\hline Forward & 5'-CGGCCTATATATTGGGTTGG-3' & 55.44 & \multirow[t]{2}{*}{106} \\
\hline Reverse & 5'-ACGGCTACTTCGTCTTGACA-3' & 59.04 & \\
\hline \multicolumn{4}{|l|}{$G A P D H$} \\
\hline Forward & 5'-ATGGAGAAGGCTGGGGCT-3' & 60.29 & \multirow[t]{2}{*}{125} \\
\hline Reverse & 5'-ATCTTGAGGCTGTTGTCATACTTCTC-3' & 60.85 & \\
\hline
\end{tabular}

EXT1, exostosin glycosyltransferase 1; WISP1, WNT1 inducible signaling pathway protein 1; TSPYL5, TSP-like 5; MTDH, metadherin; $A T A D 2$, ATPase family, AAA domain containing 2; CCNE2, cyclin E2; GAPDH, glyceraldehyde-3-phosphate dehydrogenase.

USA) was used for development of the graphs. $\mathrm{P}<0.05$ was considered to represent a statistically significant difference.

\section{Results}

Demographic characteristics. Out of 1,705 breast cancer patients registered in the Bio Bank of the Cancer Research Center of Shahid Beheshti University of Medical Sciences, a total of 312 patients were identified with tumor stages I and II; only, 85 of them had at least 5 years of follow-up records that were included for analysis. A total of 15 of these patients presented with local recurrence or metastasis during the 5 years following the curative surgery (metastatic group) and 70 had not shown any sign of local recurrence or metastasis (non-metastatic group). Therefore these 70 patients were selected and compared with the metastatic group. One of the patients in the metastatic group was deceased at the time of the study. As shown in Table II, there were no significant differences observed between the non-metastatic and metastatic groups for age $(\mathrm{P}=0.107)$, marital status $(\mathrm{P}=0.201)$, history of pregnancy $(\mathrm{P}=0.561)$, childbirth $(\mathrm{P}=0.561)$, abortion $(\mathrm{P}=0.378)$, type of abortion ( $\mathrm{P}=0.545)$, smoking $(\mathrm{P}=0.260)$, high-fat diet $(\mathrm{P}=0.464)$ and family history of breast cancer $(\mathrm{P}=0.925)$. The mean age of the control group was $42.9 \pm 9.2$ years. There were no significant differences between the mean age of the control group and that of the non-metastatic $(\mathrm{P}=0.076)$ or metastatic patient $(\mathrm{P}=0.654)$ groups. However, significant differences were observed between the non-metastatic and metastatic groups regarding the number of pregnancies and childbirths each patient had experienced (Fig. 1A and $\mathrm{B} ; \mathrm{P}=0.019$ and $\mathrm{P}=0.008$, respectively); a markedly higher number of patients in the non-metastatic group had $\geq 3$ pregnancies and/or childbirth events compared with the metastatic group. There was no significant difference between non-metastatic and metastatic groups regarding the number of abortions each patient had experienced (Fig. $1 C$; $\mathrm{P}=0.551$ ). The mean duration of breastfeeding in the non-metastatic group was reduced compared with that in the metastatic group, but this difference was not significant $(\mathrm{P}=0.057)$.

Clinical features. With respect to the clinical findings, the non-metastatic and metastatic groups were observed to be significantly different with regard to pathology and lymphovascular invasion ( $\mathrm{LVI} ; \mathrm{P}=0.032$ and $\mathrm{P}=0.036$, respectively). Invasive lobular carcinoma was more common among the metastatic patients compared with the non-metastatic patients (31 vs. 4\%), and invasive ductal carcinoma was more common in the non-metastatic patients compared with the metastatic patients (69 vs. 88\%). Notably, an increased percentage of the non-metastatic group was LVI-positive compared to the metastatic group (52 vs. 18\%). In addition, a higher percentage of the metastatic patients exhibited stage II disease compared to the non-metastatic patients (53 vs. $28 \%$ ). No significant differences were observed between the patient groups for any other tumor features and clinical findings, including tumor size 


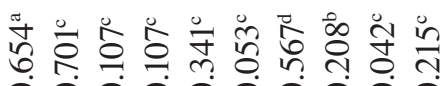

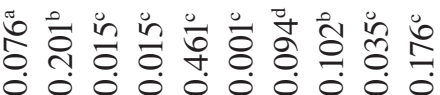

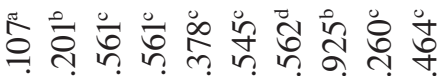

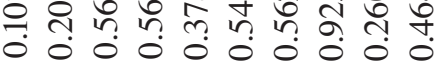

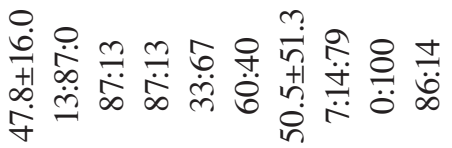

( $\mathrm{P}=0.106)$, grade $(\mathrm{P}=0.898)$, ER status $(\mathrm{P}=0.100)$, progesterone receptor status $(\mathrm{P}=0.557)$, human epidermal growth factor receptor 2 (HER2) status $(\mathrm{P}=0.589), \mathrm{P} 53$ status $(\mathrm{P}=0.611)$, diabetes $(\mathrm{P}=0.300)$, serum vitamin $\mathrm{D}$ level $(\mathrm{P}=0.057)$, surgery type $(\mathrm{P}=0.174)$, and receiving chemotherapy $(\mathrm{P}=0.268)$, radiotherapy $(\mathrm{P}=0.437)$, estrogen-progesterone $(\mathrm{P}=0.585)$ and other hormone therapy $(\mathrm{P}=0.622$; Table III).

Gene expression levels. For evaluation of mRNA expression of EXT1, WISP1, ATAD2, TSPYL5, MTDH and CCNE2 genes, qPCR was performed (Fig. 2). The results revealed that expression of EXT1 and WISPI was significantly decreased in the metastatic group compared to the control $(\mathrm{P}=0.015$ and $\mathrm{P}=0.012$, respectively) and non-metastatic $(\mathrm{P}<0.001$ and $\mathrm{P}<0.001)$ groups, while no significant difference was observed for the expression of these genes between the control and non-metastatic groups ( $\mathrm{P}=0.803$ and $\mathrm{P}=0.955$, respectively). The expression of TSPYL5, MTDH and ATAD2 genes in metastatic $(\mathrm{P}=0.002, \mathrm{P}=0.018$ and $\mathrm{P}=0.016$, respectively) and non-metastatic $(\mathrm{P}=0.038, \mathrm{P}=0.045$ and $\mathrm{P}=0.000$, respectively) groups was significantly decreased compared to the control group. In addition, a significant reduction was observed in the expression of TSPYL5 in the metastatic group compared to the non-metastatic group $(\mathrm{P}=0.040)$, and in that of $A T A D 2$ in the non-metastatic group compared to the metastatic group $(\mathrm{P}=0.014)$. No significant difference was observed in the expression of $M T D H$ between the metastatic and non-metastatic groups $(\mathrm{P}=0.293)$. The mRNA expression of CCNE2 in the metastatic and non-metastatic groups was significantly increased compared with the control $(\mathrm{P}=0.002$ and $\mathrm{P}=0.001)$, while expression of this gene was not altered in the metastatic group compared to the non-metastatic group $(\mathrm{P}=0.746)$.

Correlation between expressions of genes. As depicted in Fig. 3 , there was a significant strong positive correlation between expression of WISPI and TSPYL5 ( $\mathrm{r}=0.743$; $\mathrm{P}<0.001)$, and significant weak positive correlations between EXT1 and WISPI $(\mathrm{r}=0.293$; $\mathrm{P}=0.009)$, EXT1 and TSPYL5 ( $\mathrm{r}=0.316 ; \mathrm{P}=0.005)$, and TSPYL5 and $M T D H(\mathrm{r}=0.395 ; \mathrm{P}<0.001)$. In addition, non-significant weak positive correlations were observed between expression of TSPYL5 and ATAD2 (r=0.244; $\mathrm{P}=0.102)$ and $M T D H$ and ATAD2 $(\mathrm{r}=0.245 ; \mathrm{P}=0.105)$, and weak non-significant negative correlations were observed between TSPYL5 and CCNE2 ( $\mathrm{r}=-0.211$; $\mathrm{P}=0.129)$ and $M T D H$ and $C C N E 2(\mathrm{r}=-0.200 ; \mathrm{P}=0.154)$.

Correlation between gene expression and demographic characteristics. As given in Table IV, expression of WISPI was correlated with age $(\mathrm{r}=0.264 ; \mathrm{P}=0.026)$ and family history of breast cancer $(\mathrm{r}=0.209 ; \mathrm{P}=0.088)$, while no association was observed between WISP1 expression and other demographic characteristics of the patients (for all, $\mathrm{r}<0.200$; $\mathrm{P}>0.05$ ). The expression of TSPYL5 was correlated with abortion $(\mathrm{r}=0.200$; $\mathrm{P}=0.094)$, smoking $(\mathrm{r}=0.243 ; \mathrm{P}=0.044)$ and family history of breast cancer $(\mathrm{r}=0.340 ; \mathrm{P}=0.005) ;$ TSPYL5 expression was significantly higher among patients who had a family history of the disease $(\mathrm{P}=0.002)$ and those who were smokers $(\mathrm{P}=0.048)$. However, no correlation was observed between TSPYL5 and other demographic features (for all, $\mathrm{r}<0.200$; $\mathrm{P}>0.05$ ). The $M T D H$ expression was also correlated with family history of breast cancer $(\mathrm{r}=0.203 ; \mathrm{P}=0.100)$, while it was not correlated with other demographic features (for all, $\mathrm{r}<0.200 ; \mathrm{P}>0.05$ ). 
Table III. Clinical findings of the breast cancer patients in the present study.

\begin{tabular}{|c|c|c|c|}
\hline Variable & Non-metastatic & Metastatic & P-value \\
\hline Pathology, IDC: DCIS: IDC/DCIS: ILC: IDC/ILC, \% & $88: 4: 2: 4: 2$ & 69:0:0:31:0 & $0.032^{\mathrm{a}}$ \\
\hline Stage, I:II, \% & $72: 28$ & $47: 53$ & $0.058^{\mathrm{b}}$ \\
\hline Grade, $1: 2: 3, \%$ & $10: 76: 14$ & 9:82:9 & $0.898^{\mathrm{a}}$ \\
\hline Lymphovascular invasion, $+:-, \%$ & $52: 48$ & 18:82 & $0.036^{\mathrm{b}}$ \\
\hline Estrogen receptor, +: -, \% & 100:0 & $100: 0$ & $1.000^{\mathrm{a}}$ \\
\hline Progesterone receptor, $+:-, \%$ & $96: 4$ & $93: 7$ & $0.557^{\mathrm{b}}$ \\
\hline Human epidermal growth factor receptor $2,+:-, \%$ & $37: 63$ & $36: 64$ & $0.589^{\mathrm{b}}$ \\
\hline $\mathrm{P} 53,+:-, \%$ & $27: 73$ & $20: 80$ & $0.611^{\mathrm{b}}$ \\
\hline Tumor size, $\mathrm{cm}$, mean $\pm \mathrm{SD}$ & $2.1 \pm 0.9$ & $2.6 \pm 1.5$ & $0.424^{\mathrm{c}}$ \\
\hline Surgery type, BCS: MRM: BCS/MRM, \% & $50: 32: 18$ & 50:50:0 & $0.174^{\mathrm{a}}$ \\
\hline Chemotherapy, yes: no, \% & 90:10 & $75: 25$ & $0.268^{\mathrm{b}}$ \\
\hline Radiotherapy, yes: no, \% & $86: 14$ & $93: 7$ & $0.437^{\mathrm{b}}$ \\
\hline Hormone therapy, yes: no, $\%$ & $91: 9$ & $93: 7$ & $0.622^{\mathrm{b}}$ \\
\hline Receiving estrogen and progesterone, yes: no, $\%$ & $12: 88$ & $13: 87$ & $0.585^{\mathrm{b}}$ \\
\hline Vitamin D, ng/ml, mean \pm SD & $27.2 \pm 25.2$ & $36.9 \pm 20.0$ & $0.225^{\mathrm{c}}$ \\
\hline Diabetes, yes: no, $\%$ & 9:91 & $0: 100$ & $0.300^{\mathrm{b}}$ \\
\hline
\end{tabular}

${ }^{a} \chi^{2}$ test. ${ }^{b}$ Fisher's exact test. ${ }^{c}$ Mann-Whitney U test. IDC, invasive ductal carcinoma; DCIS, ductal carcinoma in situ; ILC, infiltrating lobular carcinoma; BCS, breast-conserving surgery; MRM, modified radical mastectomy; SD, standard deviation.

A

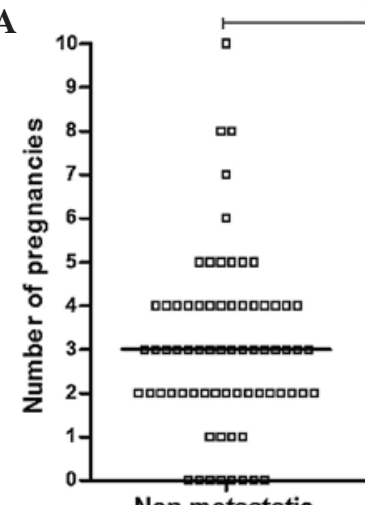

Non-metastatic
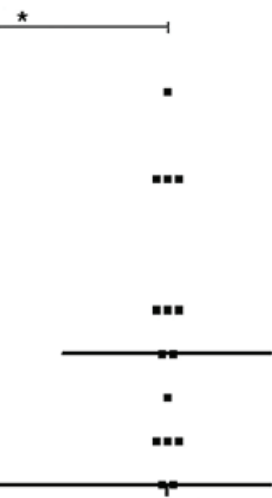

Metastatic

C
B

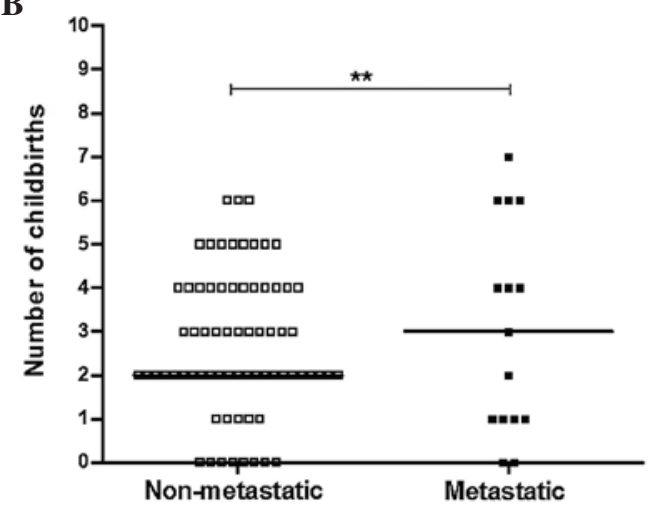

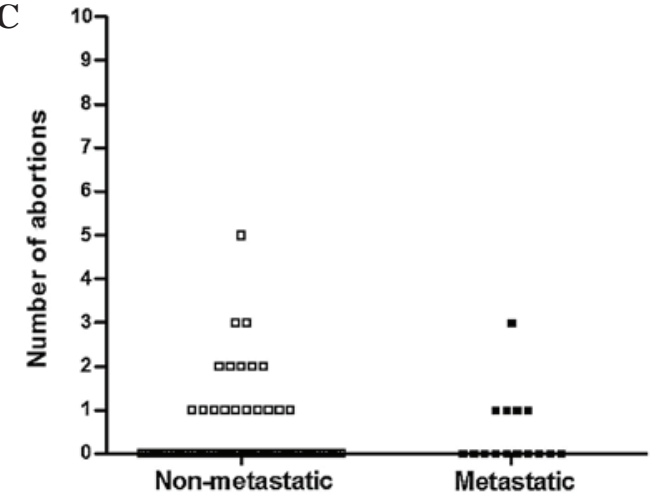

Figure 1. Comparison of number of pregnancies, childbirths and abortions between metastatic and non-metastatic groups. A higher percentage of patients in the non-metastatic group had (A) $\geq 3$ pregnancies and (B) childbirth experiences. (C) However, no significant difference was observed between the number of abortions in the metastatic and non-metastatic groups. " and ${ }^{* *}$ represent $\mathrm{P}<0.05$ and $<0.01$, respectively.

The expression of $A T A D 2$ was only correlated with abortion $(\mathrm{r}=0.207 ; \mathrm{P}=0.205)$ and smoking $(\mathrm{r}=0.277 ; \mathrm{P}=0.092)$. The expressions of EXT1 and CCNE2 were not correlated with none of the demographic features (for all, $\mathrm{r}<0.200 ; \mathrm{P}>0.05$ ).
Correlation between gene expression and clinical features. As presented in Table V, expression of EXT1 demonstrated a significant correlation with hormone therapy $(\mathrm{r}=0.368$; $\mathrm{P}=0.002$ ), but it did not exhibit any correlation with other 


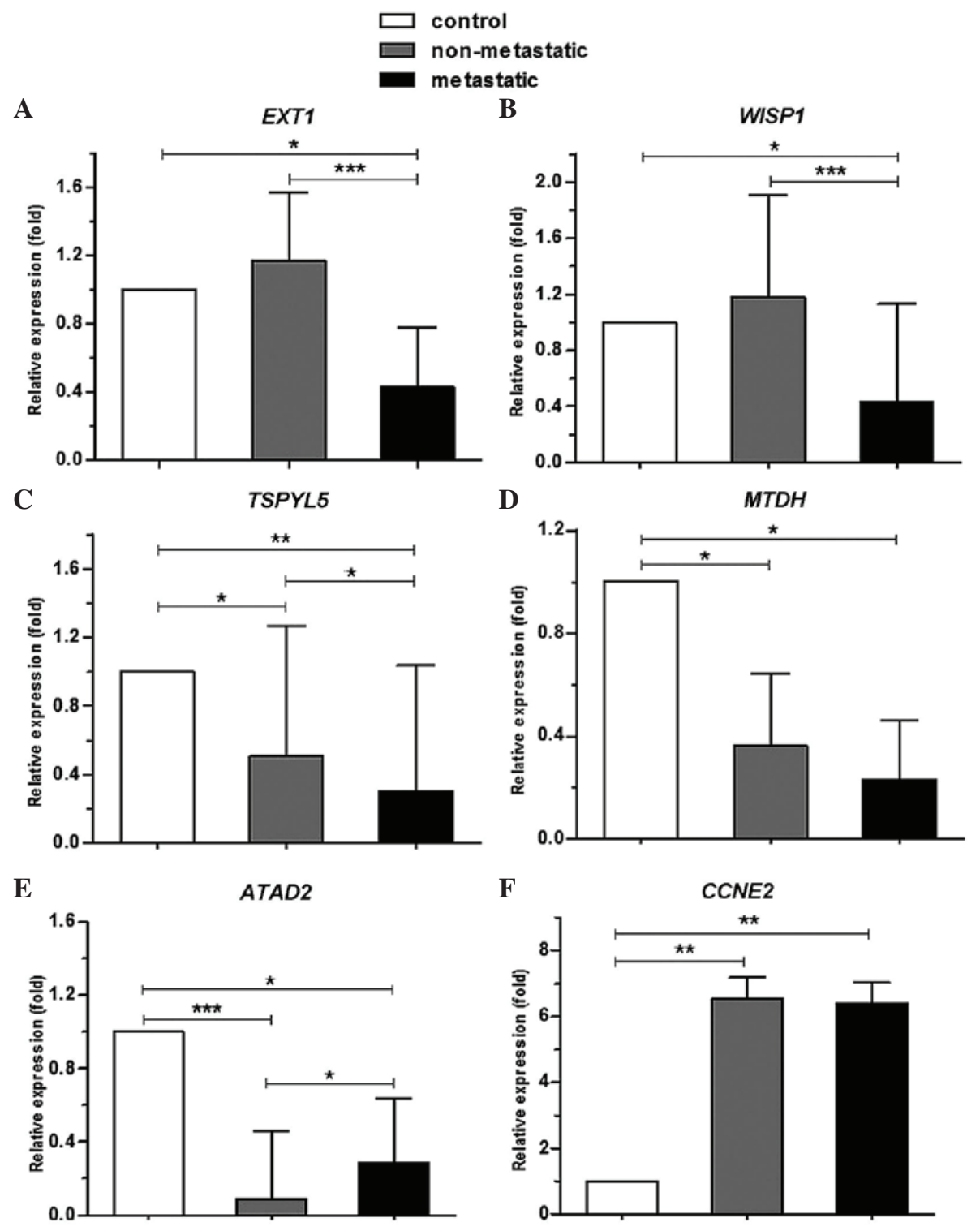

Figure 2. Comparison of mRNA expression of EXT1, WISP1, ATAD2, TSPYL5, MTDH and CCNE2 genes between control, metastatic and non-metastatic groups. (A and B) The expression of EXT1 and WISP1 was significantly decreased in the metastatic group compared to the control and non-metastatic groups. (C-E) The expression of TSPYL5, MTDH and ATAD2 was significantly decreased in metastatic and non-metastatic groups compared to the control. (F) The expression of $C C N E 2$ was significantly increased in the metastatic and non-metastatic groups compared to the control. ${ }^{* * *}$ and ${ }^{* * *}$ represent $\mathrm{P}<0.05,<0.01$ and $<0.001$, respectively. EXT1, exostosin glycosyltransferase 1; WISP1, WNT1 inducible signaling pathway protein 1; TSPYL5, TSP-like 5; MTDH, metadherin; ATAD2, ATPase family, AAA domain containing 2; CCNE2, cyclin E2.

clinical features of the patients (for all, $\mathrm{r}<0.200 ; \mathrm{P}>0.05$ ). WISPI expression was correlated with tumor size $(\mathrm{r}=-0.242$; $\mathrm{P}=0.047)$ vitamin $\mathrm{D}$ level $(\mathrm{r}=0.220 ; \mathrm{P}=0.242)$, surgery type $(\mathrm{r}=0.240 ; \mathrm{P}=0.047)$ and hormone therapy $(\mathrm{r}=0.264 ; \mathrm{P}=0.026)$, whereas no correlation was found between WISPI expression and other clinical features (for all, $\mathrm{r}<0.200 ; \mathrm{P}>0.05$ ). TSPYL5 demonstrated correlations with LVI $(\mathrm{r}=0.309 ; \mathrm{P}=0.016)$, tumor size $(r=-0.235 ; P=0.054)$, surgery type $(r=0.276 ; P=0.022)$, radiotherapy $(\mathrm{r}=0.213 ; \mathrm{P}=0.122)$ and hormone therapy $(\mathrm{r}=0.247 ; \mathrm{P}=0.038)$. However, no correlation was seen between TSPYL5 and other clinical features (for all, $\mathrm{r}<0.200 ; \mathrm{P}>0.05$ ). ATAD2 demonstrated correlations only with LVI $(\mathrm{r}=0.200$; $\mathrm{P}=0.272)$, HER2 ( $\mathrm{r}=0.272 ; \mathrm{P}=0.108)$, vitamin $\mathrm{D}$ level ( $\mathrm{r}=0.451$; $\mathrm{P}=0.106)$ and diabetes $(\mathrm{r}=0.274 ; \mathrm{P}=0.092) . C C N E 2$ expression was correlated with pathology $(\mathrm{r}=0.270 ; \mathrm{P}=0.077)$, LVI $(\mathrm{r}=0.223 ; \mathrm{P}=0.185), \mathrm{P} 53(\mathrm{r}=0.318 ; \mathrm{P}=0.113)$, surgery type $(\mathrm{r}=0.319 ; \mathrm{P}=0.033)$, chemotherapy $(\mathrm{r}=0.270 ; \mathrm{P}=0.077)$ and estrogen-progesterone therapy $(\mathrm{r}=0.310 ; \mathrm{P}=0.062)$. However, no correlation was observed between $C C N E 2$ expression and other clinical features of the patients (for all, $\mathrm{r}<0.200 ; \mathrm{P}>0.05$ ).

\section{Discussion}

Following a large number of investigations, the gene expression profiling approach has been established to serve as an appropriate predictor for the clinical outcome of human breast cancer $(27,28)$. The $8 \mathrm{q} 22-24$ position has recently drawn the interest of a number of investigators in this field, worldwide (13-17,29). However, to date the majority of relevant publications contradict each other (18-20,30-32), leaving the prognostic value of the 8q22-24 position uncertain. Therefore, in the current study the mRNA expression patterns of WISPI, 


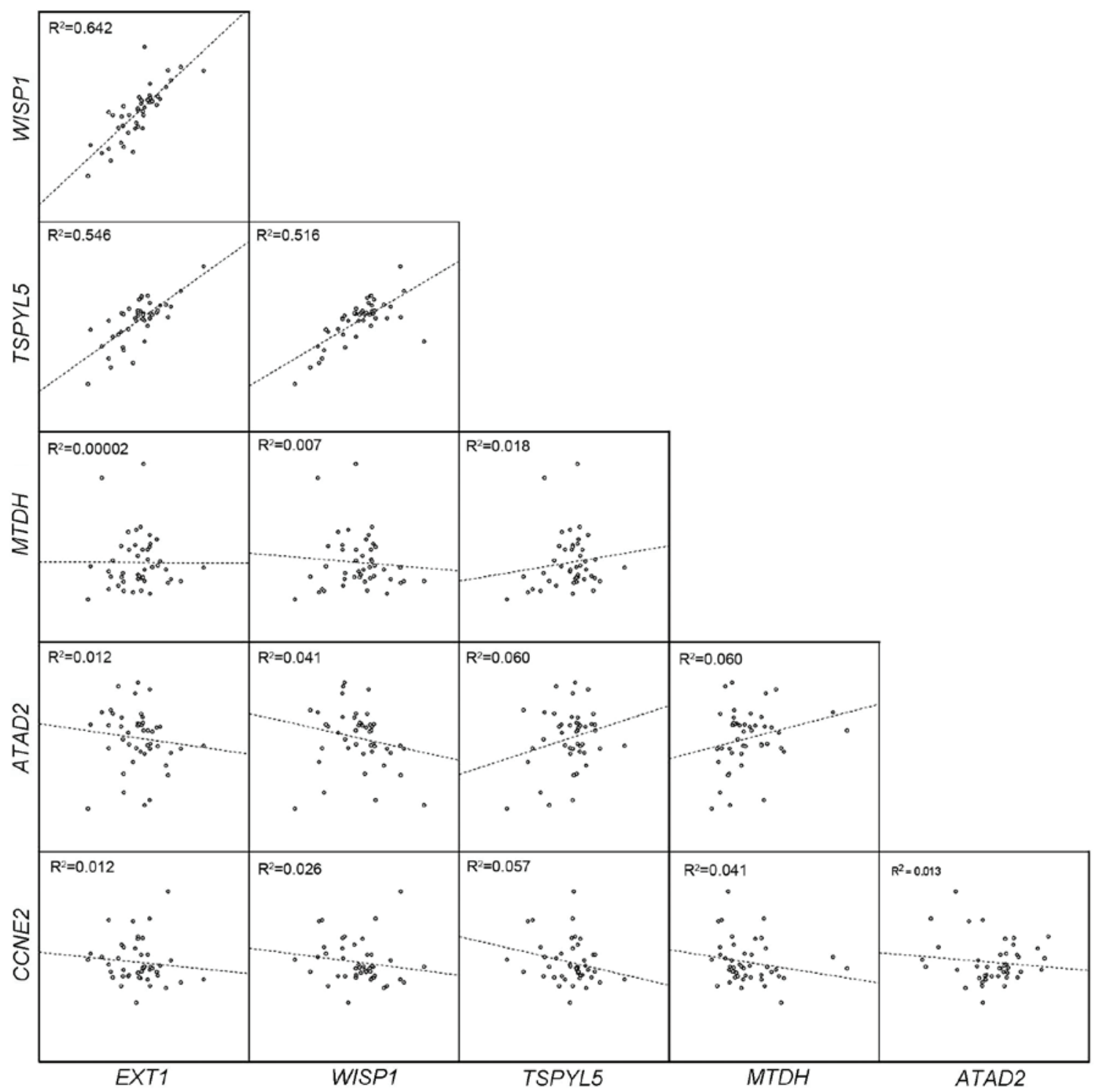

Figure 3. Evaluation of correlations between mRNA expression of EXT1, WISP1, ATAD2, TSPYL5, MTDH and CCNE2 genes in the present study. There were marked positive correlations between EXT1, WISP1 and TSPYL5 expression. EXT1, exostosin glycosyltransferase 1; WISP1, WNT1 inducible signaling pathway protein 1; TSPYL5, TSP-like 5; MTDH, metadherin; ATAD2, ATPase family, AAA domain containing 2; CCNE2, cyclin E2.

EXT1, ATAD2, TSPYL5, MTDH and CCNE2 genes, located at the $8 \mathrm{q} 22-24$ position, were examined in metastatic and non-metastatic early-stage breast cancers. However, the results of the present study contradicted numerous previous reports. All patients included in the present study were lymph-node negative, ER positive and exhibited stage I and II breast cancer, which may be a logical explanation for this observed difference. By contrast, the majority of previous investigations have included patients with advanced stage breast cancers, regardless of ER status. Furthermore, to the best of our knowledge, the present study is the first to investigate target genes in lymph node-negative early stage breast cancers.

The WISPI gene is located in the 8q24.1-8q24.3 region, and encodes WNT1-inducible-signaling pathway protein 1, a microcellular protein that is also known as CCN4, in humans (8). An increasing number of studies indicate that WISP1 may be implicated in the development and progression of various types of cancer, suggesting this molecule may be a marker for disease $(6,18,26,33)$. However, conflicting data exist regarding the stimulatory or suppressive role of WISP1 in cancer development (17-19). In the current study, it was observed that the mRNA expression of WISP1 in non-metastatic breast cancer patients was unchanged compared to normal individuals, while its expression significantly declined in metastatic patients. This finding is in accordance with Davies et al (19) who reported WISPI as a tumor suppressor gene; it was observed that mRNA transcripts of WISP1 were decreased in node-positive breast cancer patients who subsequently developed metastasis and died. In line with results of Davies et al (19), the decline observed in the expression of the WISPI gene in the present study appears to be associated with aggressive behavior of the tumor in metastatic breast cancer. However, the results of other previous studies contradict this finding. In contrast to the present study, Xie et al (17) observed that expression level of WISPI was elevated in primary breast cancer, and this may have contributed to more advanced features of the disease. Chen et al (18) also reported that increased expression of WISPI may be associated with the pathogenesis of primary lung cancers. 
Table IV. Correlation between gene expression and demographic characteristics of breast cancer patients.

\begin{tabular}{|c|c|c|c|c|c|c|}
\hline \multirow[b]{2}{*}{ Variable } & \multicolumn{6}{|c|}{ Gene name } \\
\hline & EXT1 & WISPI & TSPYL5 & $M T D H$ & $A T A D 2$ & CCNE2 \\
\hline \multicolumn{7}{|l|}{$\mathrm{Age}^{\mathrm{a}}$} \\
\hline $\mathrm{r}$ coefficient & 0.074 & 0.264 & 0.195 & -0.069 & -0.179 & -0.098 \\
\hline P-value & 0.542 & 0.026 & 0.103 & 0.570 & 0.277 & 0.516 \\
\hline \multicolumn{7}{|l|}{ Marital status $^{\mathrm{b}}$} \\
\hline $\mathrm{r}$ coefficient & 0.068 & 0.199 & 0.067 & 0.124 & 0.134 & 0.060 \\
\hline P-value & 0.584 & 0.103 & 0.590 & 0.317 & 0.415 & 0.698 \\
\hline \multicolumn{7}{|c|}{ Pregnancy or childbirth ${ }^{\mathrm{b}}$} \\
\hline$r$ coefficient & 0.150 & 0.113 & 0.054 & 0.029 & 0.026 & 0.145 \\
\hline P-value & 0.212 & 0.348 & 0.653 & 0.812 & 0.877 & 0.337 \\
\hline \multicolumn{7}{|l|}{ Abortion $^{\mathrm{b}}$} \\
\hline$r$ coefficient & 0.089 & 0.101 & 0.200 & 0.124 & 0.207 & 0.048 \\
\hline P-value & 0.462 & 0.403 & 0.094 & 0.308 & 0.205 & 0.749 \\
\hline \multicolumn{7}{|c|}{ Duration of breastfeeding ${ }^{a}$} \\
\hline $\mathrm{r}$ coefficient & -0.094 & -0.007 & 0.088 & 0.042 & 0.060 & 0.059 \\
\hline P-value & 0.440 & 0.955 & 0.470 & 0.733 & 0.718 & 0.698 \\
\hline \multicolumn{7}{|l|}{ Smoking ${ }^{\mathrm{b}}$} \\
\hline $\mathrm{r}$ coefficient & 0.142 & 0.142 & 0.243 & 0.185 & 0.277 & 0.006 \\
\hline P-value & 0.244 & 0.244 & 0.044 & 0.131 & 0.092 & 0.969 \\
\hline \multicolumn{7}{|l|}{ High-fat diet ${ }^{a}$} \\
\hline $\mathrm{r}$ coefficient & 0.178 & 0.186 & 0.173 & 0.088 & 0.165 & 0.036 \\
\hline P-value & 0.160 & 0.141 & 0.170 & 0.491 & 0.343 & 0.824 \\
\hline \multicolumn{7}{|c|}{ Family history ${ }^{\mathrm{b}}$} \\
\hline $\mathrm{r}$ coefficient & 0.164 & 0.209 & 0.340 & 0.203 & 0.059 & 0.183 \\
\hline P-value & 0.183 & 0.088 & 0.005 & 0.100 & 0.726 & 0.228 \\
\hline
\end{tabular}

EXT1, exostosin glycosyltransferase 1; WISP1, WNT1 inducible signaling pathway protein 1; TSPYL5, TSP-like 5; MTDH, metadherin; $A T A D 2$, ATPase family, AAA domain containing 2; CCNE2, cyclin E2. 'Pearson correlation test. 'Spearman's ranked correlation test.

The present study also observed that the expression of WISP1 was associated with a patient's age, serum vitamin D level, tumor size, surgery type and hormone therapy, but showed no association with stage, grade, pathological type and disease features. The negative correlation of WISPl with a patient's age, serum vitamin D level and tumor size does not support the hypothesis that a reduced level of WISPI is a marker for tumor progression or aggressive features. However, referring to the relevant literature, no evidence regarding the correlation of WISPI with any demographic or pathological features in breast cancer was identified. Furthermore, Xie et al (34) reported no significant association between expression of WISPI and pathological features, including tumor grade and stage, in primary glioma. Taken together, the results of the present study may suggest WISP1 as a prognostic marker for breast cancer metastasis; though, whether it is a tumor stimulator or suppressor remains to be elucidated.

The EXT1 gene is located at 8q24.11, and encodes exostosin glycosyltransferase 1, primarily known to serve as a tumor suppressor (30). However, there is evidence suggesting a tumor promoting role for EXT1 (32,35,36). For example, it has been demonstrated that expression of the EXT1 gene was amplified following treatment with heparan sulfate proteoglycans, which indicated that, as a glycosylation enzyme, EXT1 participates in heparan biosynthesis, and therefore potentially contributes to the proliferation and invasive potential of breast cancer epithelial cells in ER-negative tumors $(32,35)$. Furthermore, an increased plasma level of EXT1 has been associated with tumorigenesis in cholangiocarcinoma, a form of malignancy in the biliary duct system (36). In the current study, the mRNA expression pattern of EXT1 was similar to that of WISP1. Furthermore, positive correlation was observed between the expression of the EXT1 and WISPl genes, and unlike the other investigated genes, EXT1 was not associated with the demographic or clinical features of the patients. Based on these findings and following investigations in the future, monitoring mRNA levels of EXT1 along with WISPI may assist with assessing the risk of breast cancer metastasis.

The TSPYL5 gene is located at 8q22.1, and encodes the testis-specific Y encoded like protein 5 (24). Elevated expression of this gene has been implicated in breast oncogenesis and poor prognosis, via suppression of P53 function (24). Although little is known about the role of TSPYL5 in the context of cancer, it has been previously suggested to serve as a transcription factor for a number of genes involved in ER-positive breast cancer (37). In 
Table V. Correlation between gene expression and clinical features of breast cancer patients.

\begin{tabular}{|c|c|c|c|c|c|c|}
\hline \multirow[b]{2}{*}{ Variable } & \multicolumn{6}{|c|}{ Gene name } \\
\hline & EXT1 & WISPl & TSPYL5 & $M T D H$ & $A T A D 2$ & CCNE2 \\
\hline \multicolumn{7}{|l|}{ Pathology $\mathrm{y}^{\mathrm{b}}$} \\
\hline r coefficient & 0.191 & 0.100 & 0.058 & 0.070 & 0.187 & 0.270 \\
\hline P-value & 0.116 & 0.414 & 0.638 & 0.570 & 0.266 & 0.077 \\
\hline \multicolumn{7}{|l|}{ Stage $^{b}$} \\
\hline r coefficient & 0.166 & 0.188 & 0.155 & 0.021 & 0.066 & 0.061 \\
\hline P-value & 0.174 & 0.122 & 0.203 & 0.865 & 0.693 & 0.696 \\
\hline \multicolumn{7}{|l|}{ Grade $^{b}$} \\
\hline r coefficient & 0.052 & 0.070 & 0.110 & 0.066 & 0.056 & 0.009 \\
\hline P-value & 0.688 & 0.584 & 0.389 & 0.606 & 0.761 & 0.956 \\
\hline \multicolumn{7}{|c|}{ Lymphovascular invasion $^{\mathrm{b}}$} \\
\hline r coefficient & 0.040 & 0.182 & 0.309 & 0.186 & 0.200 & 0.223 \\
\hline P-value & 0.761 & 0.161 & 0.016 & 0.152 & 0.272 & 0.185 \\
\hline \multicolumn{7}{|c|}{ Progesterone receptor $^{\mathrm{b}}$} \\
\hline r coefficient & 0.128 & 0.162 & 0.109 & 0.153 & 0.032 & 0.018 \\
\hline P-value & 0.296 & 0.184 & 0.373 & 0.211 & 0.848 & 0.909 \\
\hline \multicolumn{7}{|c|}{ Human epidermal growth factor receptor ${ }^{b}$} \\
\hline r coefficient & 0.150 & 0.075 & 0.177 & 0.150 & 0.272 & 0.049 \\
\hline P-value & 0.243 & 0.561 & 0.168 & 0.243 & 0.108 & 0.759 \\
\hline \multicolumn{7}{|l|}{$\mathrm{P}^{5} 3^{\mathrm{b}}$} \\
\hline r coefficient & 0.074 & 0.032 & 0.111 & 0.037 & 0.043 & 0.318 \\
\hline P-value & 0.642 & 0.839 & 0.485 & 0.817 & 0.856 & 0.113 \\
\hline \multicolumn{7}{|l|}{ Tumor size ${ }^{a}$} \\
\hline r coefficient & -0.059 & -0.242 & -0.235 & -0.014 & -0.084 & 0.020 \\
\hline P-value & 0.630 & 0.047 & 0.054 & 0.911 & 0.622 & 0.900 \\
\hline \multicolumn{7}{|l|}{ Surgery type ${ }^{b}$} \\
\hline r coefficient & 0.198 & 0.240 & 0.276 & 0.028 & 0.221 & 0.319 \\
\hline P-value & 0.103 & 0.047 & 0.022 & 0.821 & 0.183 & 0.033 \\
\hline \multicolumn{7}{|c|}{ Chemotherapy $^{\mathrm{b}}$} \\
\hline r coefficient & 0.191 & 0.100 & 0.058 & 0.070 & 0.187 & 0.270 \\
\hline P-value & 0.116 & 0.414 & 0.638 & 0.570 & 0.266 & 0.077 \\
\hline \multicolumn{7}{|l|}{ Radiotherapy $^{\mathrm{b}}$} \\
\hline r coefficient & 0.082 & 0.159 & 0.213 & 0.009 & 0.089 & 0.121 \\
\hline P-value & 0.557 & 0.251 & 0.122 & 0.947 & 0.624 & 0.477 \\
\hline \multicolumn{7}{|c|}{ Hormone therapy ${ }^{b}$} \\
\hline r coefficient & 0.368 & 0.264 & 0.247 & 0.083 & 0.082 & 0.092 \\
\hline P-value & 0.002 & 0.026 & 0.038 & 0.493 & 0.621 & 0.543 \\
\hline \multicolumn{7}{|c|}{ Estrogen-progesterone ${ }^{b}$} \\
\hline r coefficient & 0.019 & 0.052 & 0.025 & 0.031 & 0.171 & 0.310 \\
\hline P-value & 0.883 & 0.691 & 0.847 & 0.811 & 0.358 & 0.062 \\
\hline \multicolumn{7}{|l|}{ Vitamin $D^{a}$} \\
\hline r coefficient & 0.056 & 0.220 & 0.057 & 0.172 & 0.451 & 0.104 \\
\hline P-value & 0.767 & 0.242 & 0.766 & 0.362 & 0.106 & 0.692 \\
\hline \multicolumn{7}{|l|}{ Diabetes $^{b}$} \\
\hline r coefficient & 0.008 & 0.040 & 0.035 & 0.128 & 0.274 & 0.120 \\
\hline P-value & 0.947 & 0.739 & 0.773 & 0.292 & 0.092 & 0.425 \\
\hline
\end{tabular}


addition, Lyu et al (38) demonstrated that regulator of G-protein signaling 2 overexpression in human breast cancer MCF7 cells diminished TSPYL5 expression, and thereby inhibited growth of the cells. By contrast, in the current study, it was observed that mRNA expression of TSPYL5 was diminished in metastatic and non-metastatic breast tumors compared with normal tissues, and the expression levels declined even further in the metastatic compared to the non-metastatic tumors. Furthermore, it was observed that mRNA expression of TSPYL5 was associated with WISPI and EXT1 mRNA expression. TSPYL5 expression was also significantly associated with family history, smoking, LVI, surgery type and hormone therapy. As the expression of TSPYL5 was altered in metastatic and non-metastatic breast tumors, this gene cannot be considered as a promising prognostic tool for breast cancer metastasis, and is more likely to be implicated in the pathogenesis of the disease.

The $M T D H$ gene is located at $8 \mathrm{q} 22.1$, and encodes metadherin, also known as astrocyte elevated gene-1 protein or protein LYRIC (39). Elevated expression of the $M T D H$ gene is associated with an increased risk of metastasis of breast cancer to the lungs (31), leading to poor prognosis (40). Hu et al (16), suggested that $M T D H$ may have a dual role in inducing metastasis and chemoresistance of breast cancer with a poor prognosis. Furthermore, inhibition of $M T D H$ has been reported to enhance the sensitivity of breast cancer cells to anti-cancer agents $(22,23)$. However, unlike this previous data, the present study demonstrated that mRNA expression of $M T D H$, similar to that of TSPYL5, in metastatic and non-metastatic tumors was lower compared to normal tissues, and its expression in the metastatic tumors was reduced compared with the non-metastatic tumors. Furthermore, the expression of $M T D H$ was directly correlated with that of TSPYL5. In contrast to previous studies, the results of the present study do not suggest the $M T D H$ gene as a prognosticator for metastasis, but rather that it may be implicated in breast cancer development.

The ATAD2 gene is located at $8 \mathrm{q} 24.13$, and encodes an ATPase containing two AAA domains, as well as a bromodomain (15). Previous studies have defined a tumor-driving role for $A T A D 2$ in breast carcinomas and other malignancies $(15,21,41-43)$. Ciro et al (41) suggested that high expression levels of $A T A D 2$ result in the development of aggressive breast cancer and poor clinical outcomes for patients, potentially via enhancement of transcriptional activity of the MYC oncogene. In addition, Caron et al (42) reported that overexpression of ATAD2 in somatic cells may affect basic features of chromatin, leading to malignant transformation during the development of breast and lung cancer, and resulting in poor prognosis. Additionally, according to Kalashnikova et al (21), increased expression of $A T A D 2$ correlated with poor prognosis in breast cancer patients. Raeder et al (15) recently indicated that the amplified expression of the ATAD2 gene is associated with an aggressive nature in endometrial cancer and a poor outcome for patients. However, the results of the present study contradict those of Kalashnikova et al (21), Ciro et al (41), Caron et al (42) and Raeder et al (15). The present study observed that expression of the ATAD2 gene was significantly decreased in metastatic and non-metastatic patients compared to normal individuals, and this expression was positively correlated with TSPYL5 and $M T D H$ expression, and vitamin D level. Taken together, the results of the present study indicate that the ATAD2 gene, similar to TSPYL5 and MTDH, cannot be considered as a metastasis gene in lymph node-negative breast cancer, but may be involved in the pathogenesis of the disease.

The CCNE2 gene is located at 8q22.1, and encodes cyclin E2 protein in humans (44). It has been demonstrated to have a significant role in the pathogenesis and invasiveness of breast cancer $(25,45)$. By way of example, Li et al $(45)$ reported that the $C C N E 2$ gene is overexpressed, simultaneously with c-Myc, in human breast cancer, and potentially acts as a promoter for development of the disease. In addition, Caldon et al (46) demonstrated that increased expression of CCNE2 may be associated with drug-resistance in breast cancer cells. Furthermore, Rogers et al (47) suggested that overexpression of CCNE2 is associated with poor prognosis and decreased genomic instability in human breast cancer. In the current study, it was observed that CCNE2 is overexpressed in metastatic and non-metastatic breast tumors compared with normal tissues. Furthermore, the expression of $C C N E 2$ was negatively correlated with that of TSPYL5 and MTDH, while it did not exhibit any association with the demographic and clinical features of the patients. The results of the present study are in agreement with those of Li et al (45), Caldon et al (46) and Rogers et al (47), suggesting that amplified expression of CCNE2 is potentially implicated in breast cancer development; however, it cannot be considered as a biomarker for metastasis risk.

In conclusion, according to the results of the current study, reductions in mRNA expression levels of TSPYL5, ATAD2 and $M T D H$ and increases in CCNE2 mRNA levels may be implicated in the pathogenesis and development of human breast cancer, whereas declines in WISPI and EXT1 mRNA expression among early-stage ER-positive lymph node-negative breast cancer patients may be associated with increased risk of metastasis. Therefore, if validated in future studies considering individual genetic background and ethnic variations, the WISP1 and EXT1 genes may serve as a promising indicator of metastasis risk.

\section{Acknowledgements}

The present study was financially supported by grant no. 13012 provided from the Cancer Research Center of Shahid Beheshti University of Medical Sciences (Tehran, Iran), and is published as part of PhD dissertation project of Dr Afsoon Taghavi.

\section{References}

1. Porter PL: Global trends in breast cancer incidence and mortality. Salud Publica Mex 51 (Suppl 2): S141-S146, 2009.

2. MacMahon B: Epidemiology and the causes of breast cancer. Int J Cancer 118: 2373-2378, 2006.

3. Rossi RE, Pericleous M, Mandair D, Whyand T and Caplin ME: The role of dietary factors in prevention and progression of breast cancer. Anticancer Res 34: 6861-6875, 2014.

4. Amani D, Khalilnezhad A, Ghaderi A, Niikawa N and Yoshiura K: Transforming growth factor beta1 (TGF 31 ) polymorphisms and breast cancer risk. Tumour Biol 35: 4757-4764, 2014.

5. Vaidya JS, Baldassarre G, Thorat MA and Massarut S: Role of glucocorticoids in breast cancer. Curr Pharm Des 16: 3593-3600, 2010.

6. Planque $\mathrm{N}$ and Perbal B: A structural approach to the role of $\mathrm{CCN}$ (CYR61/CTGF/NOV) proteins in tumourigenesis. Cancer Cell Int 3: 15, 2003.

7. Tian S, Roepman P, Van't Veer LJ, Bernards R, de Snoo F and Glas AM: Biological functions of the genes in the mammaprint breast cancer profile reflect the hallmarks of cancer. Biomark Insights 5: 129-138, 2010. 
8. Holbourn KP, Acharya KR and Perbal B: The CCN family of proteins: Structure-function relationships. Trends Biochem Sci 33: 461-473, 2008

9. Martin M: Researchers hope new database becomes universal cancer genomics tool. J Natl Cancer Inst 104: 1045-1047, 2012.

10. Cingoz S, Altungoz O, Canda T, Saydam S, Aksakoglu G and Sakizli M: DNA copy number changes detected by comparative genomic hybridization and their association with clinicopathologic parameters in breast tumors. Cancer Genet Cytogenet 145 : 108-114, 2003

11. Dellas A, Torhorst J, Schultheiss E, Mihatsch MJ and Moch $\mathrm{H}$ : DNA sequence losses on chromosomes $11 \mathrm{p}$ and $18 \mathrm{q}$ are associated with clinical outcome in lymph node-negative ductal breast cancer. Clin Cancer Res 8: 1210-1216, 2002.

12. Climent J, Martinez-Climent JA, Blesa D, Garcia-Barchino MJ, Saez R, Sánchez-Izquierdo D, Azagra P, Lluch A and Garcia-Conde J: Genomic loss of 18p predicts an adverse clinical outcome in patients with high-risk breast cancer. Clin Cancer Res 8: 3863-3869, 2002

13. Horlings HM, Lai C, Nuyten DS, Halfwerk H, Kristel P, van Beers E, Joosse SA, Klijn C, Nederlof PM, Reinders MJ, et al: Integration of DNA copy number alterations and prognostic gene expression signatures in breast cancer patients. Clin Cancer Res 16: 651-663, 2010.

14. Han S, Park K, Shin E, Kim HJ, Kim JY, Kim JY and Gwak G: Genomic change of chromosome 8 predicts the response to taxane-based neoadjuvant chemotherapy in node-positive breast cancer. Oncol Rep 24: 121-128, 2010.

15. Raeder MB, Birkeland E, Trovik J, Krakstad C, Shehata S, Schumacher S, Zack TI, Krohn A, Werner HM, Moody SE, et al: Integrated genomic analysis of the $8 \mathrm{q} 24$ amplification in endometrial cancers identifies ATAD2 as essential to MYC-dependent cancers. PLoS One 8: e54873, 2013.

16. Hu G, Chong RA, Yang Q, Wei Y, Blanco MA, Li F, Reiss M, Au JL, Haffty BG and Kang Y: MTDH activation by $8 \mathrm{q} 22$ genomic gain promotes chemoresistance and metastasis of poor-prognosis breast cancer. Cancer Cell 15: 9-20, 2009.

17. Xie D, Nakachi K, Wang H, Elashoff R and Koeffler HP: Elevated levels of connective tissue growth factor, WISP-1, and CYR61 in primary breast cancers associated with more advanced features. Cancer Res 61: 8917-8923, 2001.

18. Chen PP, Li WJ, Wang Y, Zhao S, Li DY, Feng LY, Shi XL, Koeffler HP, Tong XJ and Xie D: Expression of Cyr61, CTGF, and WISP-1 correlates with clinical features of lung cancer. PLoS One 2: e534, 2007.

19. Davies SR, Watkins G, Mansel RE and Jiang WG: Differential expression and prognostic implications of the CCN family members WISP-1, WISP-2, and WISP-3 in human breast cancer. Ann Surg Oncol 14: 1909-1918, 2007.

20. Davies SR, Davies ML, Sanders A, Parr C, Torkington J and Jiang WG: Differential expression of the CCN family member WISP-1, WISP-2 and WISP-3 in human colorectal cancer and the prognostic implications. Int J Oncol 36: 1129-1136, 2010.

21. Kalashnikova EV, Revenko AS, Gemo AT, Andrews NP, Tepper CG, Zou JX, Cardiff RD, Borowsky AD and Chen HW: ANCCA/ATAD2 overexpression identifies breast cancer patients with poor prognosis, acting to drive proliferation and survival of triple-negative cells through control of B-Myb and EZH2 Cancer Res 70: 9402-9412, 2010.

22. Kong X, Moran MS, Zhao Y and Yang Q: Inhibition of metadherin sensitizes breast cancer cells to AZD6244. Cancer Biol Ther 13: 43-49, 2012.

23. Song Z, Wang Y, Li C, Zhang D and Wang X: Molecular Modification of Metadherin/MTDH impacts the sensitivity of breast cancer to doxorubicin. PLoS One 10: e0127599, 2015.

24. Epping MT, Meijer LA, Krijgsman O, Bos JL, Pandolfi PP and Bernards R: TSPYL5 suppresses p53 levels and function by physical interaction with USP7. Nat Cell Biol 13: 102-108, 2011.

25. Pegoraro S, Ros G, Ciani Y, Sgarra R, Piazza S and Manfioletti G A novel HMGA1-CCNE2-YAP axis regulates breast cancer aggressiveness. Oncotarget 6: 19087-19101, 2015.

26. Livak KJ and Schmittgen TD: Analysis of relative gene expression data using real-time quantitative PCR and the 2(-Delta Delta C(T)) Method. Methods 25: 402-408, 2001.

27. van't Veer LJ, Dai H, van de Vijver MJ, He YD, Hart AA, Mao M, Peterse HL, van der Kooy K, Marton MJ, Witteveen AT, et al Gene expression profiling predicts clinical outcome of breast cancer. Nature 415: 530-536, 2002.
28. Gevaert O, De Smet F, Timmerman D, Moreau Y and De Moor B Predicting the prognosis of breast cancer by integrating clinical and microarray data with Bayesian networks. Bioinformatics 22 . e184-e190, 2006

29. Beroukhim R, Mermel CH, Porter D, Wei G, Raychaudhuri S, Donovan J, Barretina J, Boehm JS, Dobson J, Urashima M, et al: The landscape of somatic copy-number alteration across human cancers. Nature 463: 899-905, 2010

30. McCormick C, Leduc Y, Martindale D, Mattison K, Esford LE, Dyer AP and Tufaro F: The putative tumour suppressor EXT1 alters the expression of cell-surface heparan sulfate. Nat Genet 19: 158-161, 1998 .

31. Brown DM and Ruoslahti E: Metadherin, a cell surface protein in breast tumors that mediates lung metastasis. Cancer Cell 5: 365-374, 2004

32. Julien S, Ivetic A, Grigoriadis A, QiZe D, Burford B, Sproviero D, Picco G, Gillett C, Papp SL, Schaffer L, et al: Selectin ligand sialyl-Lewis $\mathrm{x}$ antigen drives metastasis of hormone-dependent breast cancers. Cancer Res 71: 7683-7693, 2011

33. Saxena N, Banerjee S, Sengupta K, Zoubine MN and Banerjee SK: Differential expression of WISP-1 and WISP-2 genes in normal and transformed human breast cell lines. Mol Cell Biochem 228: 99-104, 2001.

34. Xie D, Yin D, Wang HJ, Liu GT, Elashoff R, Black K and Koeffler HP: Levels of expression of CYR61 and CTGF are prognostic for tumor progression and survival of individuals with gliomas. Clin Cancer Res 10: 2072-2081, 2004.

35. Okolicsanyi RK, van Wijnen AJ, Cool SM, Stein GS, Griffiths LR and Haupt LM: Heparan sulfate proteoglycans and human breast cancer epithelial cell tumorigenicity. J Cell Biochem 115: 967-976, 2014

36. Khoontawad J, Hongsrichan N, Chamgramol Y, Pinlaor P, Wongkham C, Yongvanit P, Pairojkul C, Khuntikeo N, Roytrakul S, Boonmars T and Pinlaor S: Increase of exostosin 1 in plasma as a potential biomarker for opisthorchiasis-associated cholangiocarcinoma. Tumour Biol 35: 1029-1039, 2014.

37. Liu M, Ingle JN, Fridley BL, Buzdar AU, Robson ME, Kubo M, Wang L, Batzler A, Jenkins GD, Pietrzak TL, et al: TSPYL5 SNPs: Association with plasma estradiol concentrations and aromatase expression. Mol Endocrinol 27: 657-670, 2013.

38. Lyu JH, Park DW, Huang B, Kang SH, Lee SJ, Lee C, Bae YS, Lee JG and Baek SH: RGS2 suppresses breast cancer cell growth via a MCPIP1-dependent pathway. J Cell Biochem 116: 260-267, 2015.

39. Lee SG, Su ZZ, Emdad L, Sarkar D and Fisher PB: Astrocyte elevated gene-1 (AEG-1) is a target gene of oncogenic Ha-ras requiring phosphatidylinositol 3-kinase and c-Myc. Proc Natl Acad Sci USA 103: 17390-17395, 2006.

40. van de Vijver MJ, He YD, van't Veer LJ, Dai H, Hart AA, Voskuil DW, Schreiber GJ, Peterse JL, Roberts C, Marton MJ, et al: A gene-expression signature as a predictor of survival in breast cancer. N Engl J Med 347: 1999-2009, 2002

41. Ciró M, Prosperini E, Quarto M, Grazini U, Walfridsson J, McBlane F, Nucifero P, Pacchiana G, Capra M, Christensen J and Helin K: ATAD2 is a novel cofactor for MYC, overexpressed and amplified in aggressive tumors. Cancer Res 69: 8491-8498, 2009.

42. Caron C, Lestrat C, Marsal S, Escoffier E, Curtet S, Virolle V, Barbry P, Debernardi A, Brambilla C, Brambilla E, et al: Functional characterization of ATAD2 as a new cancer/testis factor and a predictor of poor prognosis in breast and lung cancers. Oncogene 29: 5171-5181, 2010.

43. Hsia EY, Kalashnikova EV, Revenko AS, Zou JX, Borowsky AD and Chen HW: Deregulated E2F and the AAA+ coregulator ANCCA drive proto-oncogene ACTR/AIB1 overexpression in breast cancer. Mol Cancer Res 8: 183-193, 2010.

44. Gudas JM, Payton M, Thukral S, Chen E, Bass M, Robinson MO and Coats S: Cyclin E2, a novel G1 cyclin that binds Cdk2 and is aberrantly expressed in human cancers. Mol Cell Biol 19: 612-622, 1999.

45. Li Z, Meng Q, Yu Q, Zhou Z and Li L: Evaluation of c-myc and CCNE2 amplification in breast cancer with quantitative multi-gene fluorescence in-situ hybridization. Zhonghua Bing Li Xue Za Zhi 43: 455-458, 2014 (In Chinese).

46. Caldon CE, Sergio CM, Kang J, Muthukaruppan A, Boersma MN, Stone A, Barraclough J, Lee CS, Black MA, Miller LD, et al: Cyclin E2 overexpression is associated with endocrine resistance but not insensitivity to CDK2 inhibition in human breast cancer cells. Mol Cancer Ther 11: 1488-1499, 2012.

47. Rogers S, Gloss BS, Lee CS, Sergio CM, Dinger ME, Musgrove EA, Burgess A and Caldon CE: Cyclin E2 is the predominant E-cyclin associated with NPAT in breast cancer cells. Cell Div 10: 1, 2015. 